\title{
An exploratory study on academic staff perception towards blended learning in higher education
}

\author{
Bokolo Anthony Jnr. ${ }^{1}$ (D)
}

Received: 14 June 2021 / Accepted: 4 August 2021 / Published online: 13 September 2021

(C) The Author(s) 2021

\begin{abstract}
As the years progresses, higher education has move towards implementing Blended Learning (BL) which is a combination of face-to-face and online mode of teaching and learning which have continued to advance in institutions all over the world. Accordingly, it is important to investigate the factors that may influence lecturers' perception towards BL approaches. Likewise, there are fewer studies that explored BL in lecturers' perspective. Therefore, this study proposed a framework based on Model of Personal Computer Utilization (MPCU) theory to examine the factors that influence lecturers' perception of BL to improve teaching quality in higher education. A total of 413 lecturers across universities, colleges, and polytechnics responded to an online survey questionnaire. Statistical Package for Social Science and Partial Least Square-Structural Equation Modelling was utilized for data analysis. The results suggest that social factors affect towards use, complexity, job fit, long term consequences, facilitating conditions, and Information Technology (IT) experience significantly influences lecturers' perception towards using BL initiatives to improve academic activities in higher education. Findings from this article support institutions in developing an understanding of the factors that can be considered to improve teaching design, as well as in improving IT for teaching and learning purposes.
\end{abstract}

Keywords Blended learning - Computer mediated teaching · Lecturer's perception · Lecturer's perspective $\cdot$ Model of personal computer utilization $\cdot$ Higher education

\section{Introduction}

Higher educational institutions are under increasing pressure to deploy pioneering technology-mediated educational approaches to accommodate diverse student academic needs. As a result, many lecturers are deploying Information

Bokolo Anthony Jnr.

anthony.j.bokolo@ntnu.no

1 Department of Computer Science, Norwegian University of Science and Technology, NTNU, 7491 Trondheim, Norway 
Technology (IT) in teaching to improve student learning. One of such initiatives is Blended Learning (BL), which is a combination of face-to-face (F2F) teaching with online teaching (River et al., 2016). BL is not a new concept, but the idea has existed for decades in domain like distance education. Thus, BL is a learning paradigm that employs more than one teaching mode with the aim of enhancing learning outcome and teaching delivery (López-Pérez et al., 2011). BL involves the integration of different modes of teaching, models of delivery and deployment of various technologies, and teaching modes to meet specific knowledge sharing, and information needs (Bokolo Jr et al., 2020). It involves the assimilation of different didactic approaches (asynchronous and/or synchronous mediums) and delivery formats such as Compact Disc Read-Only Memory (CD-ROM), videotape, Computer Assisted Instruction (CAI), and online-based learning (So \& Brush, 2008).

Furthermore, BL provides an effective approach for achieving the needs and teaching styles of academic staffs because it offers a more flexible schedule and it helps lecturers to develop important skills through F2F sessions, while concurrently providing them with prospect to reflect about their pedagogy (Carbonell et al., 2013). According to Graham et al. (2013) lecturers adopt BL as a teaching method because it helps to increase flexibility and access to course resources and increase cost efficiency. BL reduces student and lecturer's classroom time and subsequently saves staffing costs (Poon, 2012). BL possess the transformative prospective, offering institutions the opportunity to utilize technology, promotes a community of inquiry, and facilitates active and significant learning. Accordingly, findings from Anthony et al. (2019) suggested that BL helps to redesign course programme which resulted in improvements in students learning outcomes, which included better grades, higher content knowledge, and improved understanding of course contents.

Regardless of the advantages discussed above, BL method have certain disadvantages which relates to managing requirements and time, difficulties associated with using technology for novel lecturers, poor integration, teacher's skepticism, increased course workload, and decrease in academic productivity (Carbonell et al., 2013). Moreover, BL aids academic staffs to design courses with a variety of teaching and learning approaches (Anthony et al., 2019). This can be very demanding, as it involves lecturers to step away from their current pedagogy and to assess the plethora of learning and teaching options available (Bokolo Jr et al. 2020). Nonetheless, it allows for didactic innovate teaching and creativity to occur within the course syllabus, and across the institution (Graham et al., 2013; Monk et al., 2020).

Findings from prior studies (Park et al., 2016; Radovan \& Kristl, 2017) revealed that didactic approaches adopted by lecturers are based on their beliefs about teaching. Obviously, there are other factors that influence lecturers' use of BL to improve teaching quality (Anthony et al., 2019). In addition, while the benefits of BL approach have received the most attention from academicians, very limited studies did focus on investigating the factors that influence lecturer's perception towards using BL approaches for teaching (Aguti et al., 2014; Wong et al., 2020). Moreover, given the important role of lecturers in institutions and 
the limited studies that developed models to examine lecturers' engagement in this context. Understanding academic staff's viewpoint regarding BL for teaching is a valuable issue of investigation (Almutairi \& White, 2018). Therefore, this study develops a framework grounded on the Model of Personal Computer Utilization (MPCU) theory to investigate the factors that influence lecturers' perception towards BL.

The rest of the paper is ordered as follow. Section 2 presents the literature review. Section 3 is the research framework and hypotheses development. The methodology is discussed in Section 4. Findings are presented in Section 5. Section 6 are discussion and implications. Lastly, the conclusion of the article is presented in Section 7.

\section{Literature review}

This section presents theoretical background of BL, review of prior studies, and overview of model of personal computer utilization theory.

\subsection{Theoretical background of blended learning}

Presently, institutions are deploying Information and Communications Technologies (ICT) such as BL approach to deliver course syllabus content (Ahmed, 2010; Bokolo, 2021; Jnr, 2021). This approach integrates traditional F2F teaching, typically with the utilization of online teaching resources (Wong et al., 2014). BL has become increasingly deployed in institutions as it has the advantages of both online based and conventional teaching approaches (Sari \& Karsen, 2016). Findings from the literature (Lwoga \& Komba, 2015; Gawande, 2016; Radovan \& Kristl, 2017) revealed that the adoption of BL approach improves students' learning engagement and experience as it produces a positive impact on learners' perceptions of the learning environment and pedagogical approach (Chong et al., 2010). BL shifts the focus from "teaching" to "learning", which enables learners to become more involved in the academic process and more inspired and, as a result it improves their perseverance and commitment (Dečman, 2015; Kundu et al., 2021). Accordingly, Fig. 1 depicts the advantages of BL in higher education.

In other words, BL entails online learning experiences and on-campus classroom contact which encourages learners to learn in a collaborative and interactive environment at their own pace and in their own time (Carbonell et al., 2013; Poon, 2012). Typically, in a BL approach student attend traditional instructordirected F2F classes with synchronous communication, and utilize advanced web-based learning technologies, such as Learning Management System (LMS) to create hybrid environment (Wang, 2021). The experiences achieved from utilizing these tools not only support learning but also improves students' learning engagement and success (Dakduk et al., 2018; Jr et al. 2021).

Presently, the adoption of BL is increasing in institutions around the world. In fact, researchers have predicted that BL will develop as the "new pedagogical approach" in universities for course delivery (Graham et al., 2013; Jr et al. 2021). 


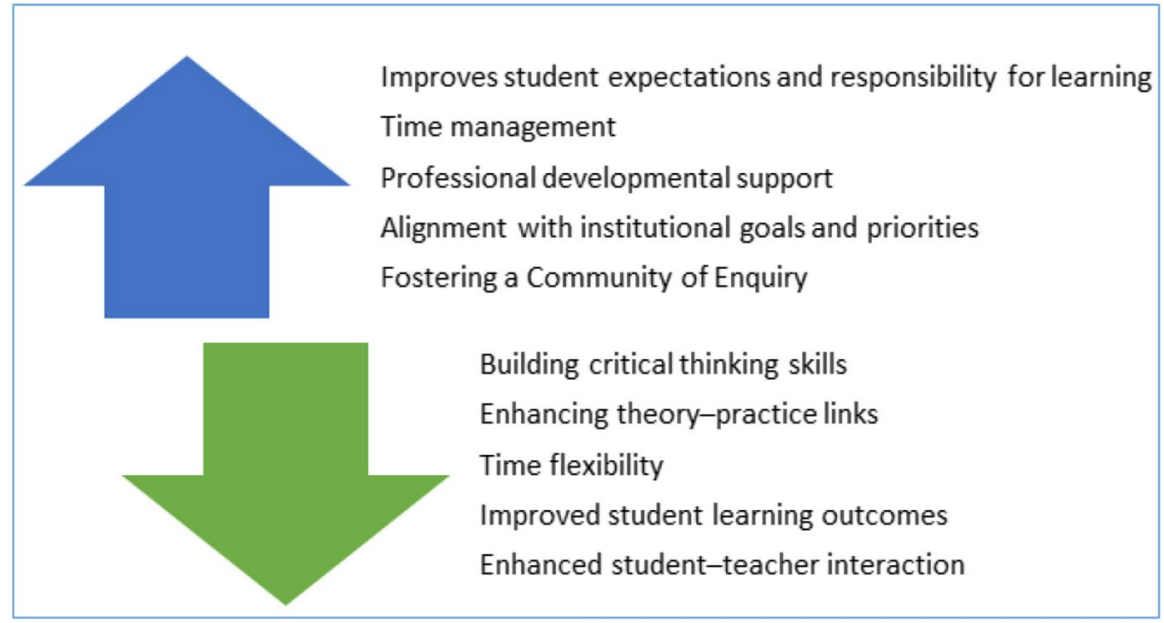

Fig. 1 Advantages of BL in higher education

BL combines different media to strengthen the interaction and direct contact with students in a course which provide motivating and meaningful learning through different synchronous and asynchronous teaching strategies (webinars, social networking, blog and forums, live chats, etc.) (Dakduk et al., 2018) as seen in Fig. 2.

Figure 2 depicts BL scenarios, where BL offers flexibility and improves teaching and learning activities, providing more opportunities for reflection

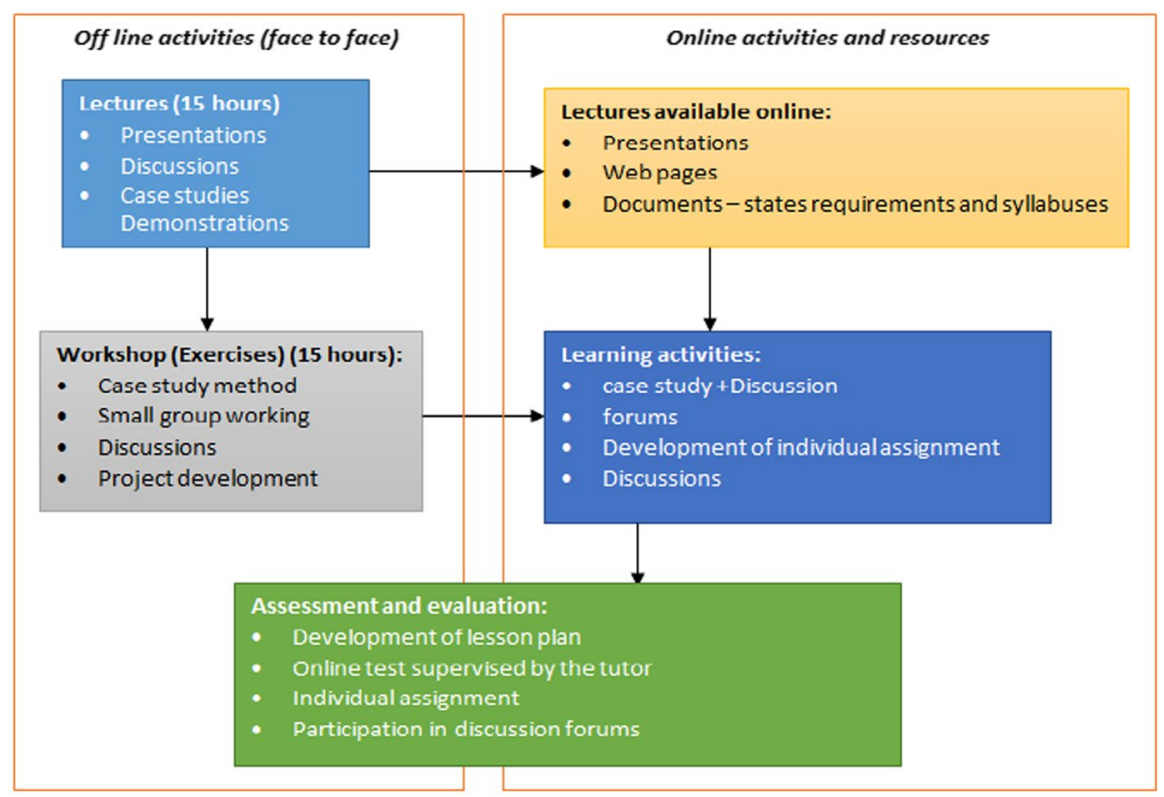

Fig. 2 BL scenarios adapted from (Tuparova \& Tuparov, 2011) 
and feedback. Currently, BL implementation is a growing trend for lecturers in Malaysia institutions because of the effectiveness of BL as an alternative educational approach (Haron et al., 2012). Likewise, very limited research has focused on examining lecturers' perception of BL for teaching, specifically in Malaysian context (Haron et al., 2012). Thus, given the essential role of lecturers in BL and the limited research in this context, investigating the factors of BL in teaching is a meaningful issue of enquiry (Dakduk et al., 2018). According to Owston et al. (2008) there is need for a model that examines lecturers' perspective to help improve design of BL pedagogy course content to improve teaching activities. But currently, prior studies explored the adoption of BL by comparing the conventional teaching and fully online mode in correlation to students' accomplishment (Jnr et al., 2020; Rahman et al., 2015). However, only few studies examined lecturers' perception of BL approach in Malaysian context (Wong et al., 2020). Given the above insights, it is apparent that there is a need to investigate the factors that influence lecturer's perception towards BL.

\subsection{Related works}

Over the year's studies have been carried out to examine factors that influenced BL adoption by lecturers. Among these studies Anthony et al. (2019) examined the role of BL for learning and teaching effectiveness in institutions. The authors developed a model based on course re-design outcome framework and innovation adoption framework to support institution in their decision making to evaluate students learning and lecturers teaching. The developed model main constructs comprised of university management, learners, academic staff, BL initiatives, practice, teaching and learning effectiveness. Survey questionnaire was employed to collect data and Structural Equation Modeling (SEM) was used to analyze the data. Teo (2019) investigated students and lecturers' intention to use technology for teaching and learning. The author aimed to explain the intention of learners and teachers to utilize technology. Technology Acceptance Model (TAM) was adopted, and data was collected using survey from 503 learners and 592 lecturers to validate applicability of TAM and SEM was employed for data analysis.

Alhabeeb and Rowley (2018) explored the factors that lead to successful e-learning in universities, through a comparative study of academic staff and students. The researchers focused to explore effectiveness of e-learning, and on the differences in perspectives of different groups of stakeholders in e-learning. Radovan and Kristl (2017) proposed a model to investigate the acceptance of BL and its impact on lecturer's activities in a virtual classroom. The authors aimed to investigate LMS adoption among lecturers and the effect of LMS use in improving teaching. Another study was carried out by Gawande (2016) where the researchers investigated lecturers' perceptions toward BL adoption at higher education institutes. The study aimed to define the determinants affecting BL adoption. The researchers identified performance expectancy, effort expectancy, facilitating conditions, social influence, behavioral intention, and teaching style as factors that predicts BL adoption. 
Similarly, Saleem et al. (2016) studied the acceptance of Moodle as a tool to support teaching and learning in a university faculty. Their study aimed to assess the influence of Unified Theory of Acceptance and Use of Technology (UTAUT) variables on lecturers' behavioral intention to employ Moodle for education activities. The study factors comprise of performance expectancy, effort expectancy, social influence, facilitating condition, behavioral intention, use behavior, gender, experience, and voluntariness of use. The authors employed interview method to collect data from 14 academic staffs. Also, Dečman (2015) examined the acceptance of e-learning in higher education environments. The authors focused to confirm the appropriateness of UTAUT within e-learning. Next, data was collection based on survey from 228 respondents and descriptive, factor analysis, and SEM was employed for data analyses.

Similarly, Gawande (2016) designed a BL model to investigate the perceptions of students at a university grounded on UTAUT. The research is aimed at identifying the drivers affecting BL adoption and verifying if teaching process was predictive of BL adoption initiatives. Questionnaire was used to collect data from 30 faculty members and Statistical Package for Social Science (SPSS) was employed to run descriptive statistics, reliability, and validity analysis. Additionally, Lwoga and Komba (2015) examined the antecedents that determine LMS continued usage intentions. Their study focused to identify the factors of continued and actual usage intentions of e-learning and issues. The identified factors comprise of performance expectancy, effort expectancy, facilitating condition, social influence, actual use, and continued usage intention. Data was collection based on survey from 300 students and interview from 20 lecturers, after which exploratory factor analysis and regression analysis was employed for further analysis.

Another study by Kocaleva et al. (2014) employed UTAUT to investigate educational activities in universities. The researchers aimed to explore the determinants that impacts e-learning adoption. The derived factors include facilitating condition, attitude, performance expectancy, social influence, effort expectancy, anxiety, self-efficacy, behavioral intention, and use behavior. Data was collection based on survey from 92 respondents and SPSS was employed for data analysis. Furthermore, Brand et al. (2011) examined the correlation of mobile learning and BL experience. The authors aimed to test the efficacy of BL for mobile learning application. Their approach comprises of performance expectancy, effort expectancy, attitude, social influence, selfefficacy, facilitating conditions, anxiety, behavioral intentions, self-managed learning, and perceived playfulness as the derived factors. Data was collected from 135 respondents and SPSS was utilized to carry out descriptive and correlation analysis.

Based on the review of 11 studies, it is found that the studies investigated the factors that influence BL adoption by lecturers. However, none of the authors examined the impact of the factors on BL using the model of personal computer utilization theory. Likewise, none of the studies offered a comprehensive framework to investigate academic staffs' perception towards BL. Therefore, more empirical evidence is necessary to explicitly show how certain factors can contribute to change lecturer perception of BL. Thus, this study fills the gap in knowledge by proposing a framework to determine the influential factors related to lecturers' perceptions of BL. This is because it is important to understand the relevant factors essential for promoting academic staffs' use of BL. 


\subsection{Overview of model of personal computer utilization theory}

Several theories have been adopted to investigate academic staffs' perception to use new technologies in didactic context such as TAM (Padilla-Meléndez et al., 2013; Teo, 2019), UTAUT (Dečman, 2015; Gawande, 2016; Kocaleva et al., 2014; Radovan \& Kristl, 2017; Saleem et al., 2016), Diffusion of Innovation (DoI) Theory (Porter et al., 2016; Bokolo Jr et al., 2020), IS success model (Lin \& Wang, 2012), etc. But there are fewer studies that have employed the model of personal computer utilization theory to examine lecturer's perception of BL. Hence, in this study the model of personal computer utilization theory is adopted in developing the research framework. The MPCU theory was developed by Thompson et al. (1991) grounded on Triandis' (1979) interpersonal behavior model from social psychology domain. It includes the social factors variable, which refers to the individual's internalization of different reference groups' interpersonal agreements, and subjective culture that the individual has made with others. MPCU's affect factor refers to the negative or positive emotional reactions of an individual in relation to a particular action (such as utilization of technology). The Triandis' (1979) model also included perceived consequences and Thompson et al. (1991) defined three types which entails one long-term and two near-term.

The near-term consequences comprise of complexity which is defined and measured as essentially the opposite of perceived ease of use in TAM, and job fit which is defined and measured similarly to perceived usefulness in TAM. Another factor is career consequences which relates to the factor of long-term consequences of use which defines the outcomes that have a payoff in the future. Lastly, Thompson et al. (1991) include facilitating conditions which refers to the environment that supports an act to be easy to be implemented. This factor is similar to the external perceived behavioral control variable of Theory of Planned Behavior (TPB) model and lastly the experience of end-user in utilizing the technology (Riemenschneider et al., 2002).

As seen in Fig. 3 MPCU can be adapted to educational context to investigate lecturer's perception of BL. MPCU theory examines actual behaviour such as utilization of technology (personal computer usage) (Taherdoost, 2018). It specifically investigates the influence of affect, facilitating condition, long-term consequences of use, perceived consequences, social influences, complexity and job fit on the perception of users of technological innovation such as BL. Results from prior studies (Al-Khaldi \& Wallace, 1999; Riemenschneider et al., 2002) indicated that job fit, social factors, long term consequences and complexity have strong influences on technology usage. Likewise, habits, facilitating condition and affect also significant effect on technology usage (Thompson et al., 1994).

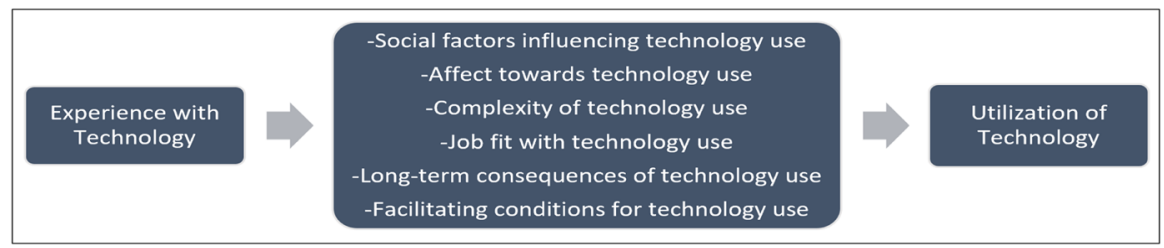

Fig. 3 Factors affecting technology use adapted from (Thompson et al., 1994) 


\section{Proposed framework and hypotheses development}

As previously mentioned, the MPCU theory is adopted in this study to examine the factors that influence lecturers' perception of BL in higher education. MPCU theory comprises of social factors, affect towards use, complexity, job fit, long term consequences, facilitating conditions, experience in technology use and perception towards BL. Each of the MPCU theory factors and related hypotheses in relation to this current study are discussed below;

\subsection{Social factors}

Social factors deal with within-institution socialization on BL use for teaching and involves commitment of institution management on improving BL (Thompson et al., 1994). The social factor involves pressure experienced by the lecturers from his/her peers regarding BL (Brand et al., 2011). Thus, this factor is associated with the lecturers' internalization of work ethics and behaviour in the institution (Riemenschneider et al., 2002). Social influence is the degree to which lecturers considered that there is requisite to use BL approach based on other people perceived belief (Anthony et al., 2019). It is the degree to which an individual lecturer perceives that his/her colleagues and other people (such as faculty members, friends, associates, university administration, and government) perceives that the use of BL in teaching is significant (Jnr, 2021; Kocaleva et al., 2014; Tarhini et al., 2017). In line with previous research (Abu-Al-Aish \& Love, 2013; Lakhal et al., 2013) social influence includes general social influence and peer influence. Recent studies (Radovan \& Kristl, 2017; Tarhini et al., 2017) have established that there is significant relationship between social influence and behavior towards BL. Accordingly, this study proposes that;

H1: Social factor will have a significant positive impact on lecturers' perception towards BL.

\subsection{Affect towards use}

Affect towards use represent academic staffs' affection and disaffection towards BL (Anthony et al., 2019). Moreover, the affective factor of lecturers' regarding BL initiatives is a function of lecturer's prior awareness and training of computer mediating teaching (Lwoga \& Komba, 2015). Accordingly, affect refers to an individual's negative or positive personal beliefs about carrying out a specific behavior. The lecturers' affect is an important factor for BL, because it entails not only the understanding and knowledge of BL, but also their attitude towards using BL for teaching (Bervell \& Umar, 2020). Respectively, lecturers who exhibit a positive attitude are more likely to perceive BL value and subsequently implement it in teaching. Furthermore, misconception that BL is not as efficient as traditional classroom may lead to negative attitude towards BL, thus influencing their perception (Ghazal et al., 2017). Apparently, affect influences lecturer's perception suggesting that a positive attitude will significantly influence intention to use BL (Teo, 2019). Therefore, this study proposes that; 
H2: There is a significant relationship between affect and lecturer's perception towards BL.

\subsection{Complexity}

Complexity denotes the difficulty that a lecturer may experience while using BL for both F2F and online delivery (Kocaleva et al., 2014). This factor relates to how complicated or how long it takes to learn how to use BL initiatives (Al-Khaldi \& Wallace, 1999). Thus, the effort required to use BL will influence lecturers' perception towards BL (Gawande, 2016). Besides, complexity specifies how easy it is for lecturers to provide steadfast learning services to support students learning for successful BL (Mondi et al., 2007). The ease of use of BL means the easiness extent to which the lecturers anticipate the target of BL is of without much effort (Ho, 2017). The ease of use of BL course materials by lecturers is important for use in BL environment (Ghazal et al., 2017). In contrast, it has been confirmed that when lecturers perceive using BL to be difficult and complex, their views about IT mediated learning incompetence will increase which results to non-acceptance of BL (Teo, 2019). Similarly, Anthony et al. (2019) stated that if lecturers perceive BL to be useful and easy to use, it is likely that lecturer's perception toward BL will be positive. Thus, this study hypothesizes that;

H3: There is a significant relationship between complexity and lecturer's perception towards BL.

\subsection{Long term consequences}

Researchers such as Dečman (2015) suggested that the consequences factor relates to how lecturers evaluate the consequences of their behavior in terms of prospective rewards and incentives or rewards to be achieved. Besides, the consequences may be negative or positive, just as they can be low or high (Saleem et al., 2016). The consequences may be seen instantly on the use of BL or may range beyond the short term to long-term effect (Kocaleva et al., 2014). Thus, if institutions provide incentives and promotions to lecturers who use BL approaches for teaching that may influence academic staffs to employ BL (Anthony et al., 2019). Accordingly, long term consequence of using BL by lecturers is a key factor for BL. Hence, lecturers' uncertainty or certainty in using BL strategies in achieving educational goals depends to a larger extent on the benefits they perceive can be achieved (Bervell \& Umar, 2020; Jnr, 2021). Therefore, this study proposes that;

H4: There is a significant relationship between long term consequences and lecturer's perception towards BL.

\subsection{Job fit}

Job fit refer to BL potential for improving academic staff teaching performance (Bath \& Bourke, 2011). Hence, if the lecturer perceives BL approach ease teaching, he/she is motivated to use BL, and this influences their perception towards BL 
(Kocaleva et al., 2014). Academic staffs will use BL for teaching if they perceive that BL would improve their current pedagogy (Gawande, 2015). In this study job fit refers to the lecturer's evaluation that using $\mathrm{BL}$ will be reasonably free of cognitive problem and measures the capability with which a student is able to easily learn via BL (Anthony et al., 2019). Additionally, job fit refers to the lecturer's judgments of his/her capabilities to execute and organize activities required to achieve improved teaching (Kocaleva et al., 2014; Mondi et al., 2007). Accordingly, job fit is reported in literature as an important factor in examining the satisfaction of lecturers (Ho, 2017), towards the belief that he or she can improve teaching (Ghazal et al., 2017). Arguably, as lecturers devote time using BL resources, this improves their job and enriches their teaching experience (Tarhini et al., 2017). Accordingly, this study hypothesizes that:

H5: There is a significant relationship between ease of use of BL towards lecturers' perception.

\subsection{Facilitating conditions}

Facilitating factors refer to the availability of support initiatives put in place by the institution to improve BL such as training, financial support, pedagogical support, technological support (Radovan \& Kristl, 2017). Thus, it is required for institution administration to provide onsite help desk support, online tutorial, availability of training, and a frequently up-to-date technological infrastructure to support BL adoption (Brand et al., 2011; Dečman, 2015). In other words, this is the lecturers' view of whether he/she has the available tangible and intangible resources (such as tools, expertise, equipment, etc.) required to use BL in teaching (Lakhal et al., 2013; Bokolo Jr et al., 2020). Accordingly, it is important to assess whether facilitating conditions has a significant impact on the lecturers' perception of BL, as lack of these facilitating resources may limit BL usage (Lwoga \& Komba, 2015; Tarhini et al., 2017). Thus, this present research theorized facilitating conditions as positively predicting lecturer's perception of BL. Accordingly, this study hypothesizes that:

H6: There is a positive relationship between supporting conditions and lecturers' perception towards BL.

\subsection{Experience in technology use}

In education domain experience in technology refers to the lecturers' prior knowledge of technological innovations, as well as the skills acquired by the lecturer from such experience (Deng et al., 2019). Researchers such as Bowyer and Chambers (2017) argued that the degree of experience in technology can encourage or discourage lecturers from adopting BL. As a result, lecturers' prior know-how may impact their ability to towards BL. Apparently due to the need for them to reflect upon teaching (Ghazal et al., 2017). Accordingly, findings from previous studies (Abu-Al-Aish \& Love, 2013; Brand et al., 2011; Dečman, 2015; Gawande, 2015; Kocaleva et al., 2014; Saleem et al., 2016) revealed that lecturer perception towards BL have a significant impact on their prior experience on technology usage. Thus, 
the familiarity and technology experience of the lecturer leads to reduce anxiety and negative attitude toward BL (Dečman, 2015; Kocaleva et al., 2014). Respectively, the experience of the lecturer in relation to technology plays a significant role in the acceptance of BL. The more experienced a lecturer is in relation technology, the more comfortable he/she will be to use BL for educational purposes (Anthony et al., 2019). Thus, this study hypothesizes that:

H7: There is a positive relationship between prior experience in technology and lecturers' perception towards BL.

\subsection{Perception towards BL}

Perception refers to the extent to which the lecturer has expressed conscious plans to use or not use BL (Saleem et al., 2016). Perception is presumed to capture the motivational attributes that influence lecturers' behavior towards BL use (Gawande, 2016). In this study perception measures if lecturers are enthusiastic to use BL for teaching (Dečman, 2015). In BL environment lecturer's perception to use BL for course design is determined by the tendency that BL can offer benefits in enhancing teaching and learning (Lakhal et al., 2013). Also, perception towards BL refers to the decision of lecturer to use BL before they actually use it and it's mostly predicted to occur in future (Anthony et al., 2019). Based on the identified factors from MPCU theory the proposed framework is developed as shown in Fig. 4.

Figure 4 depict the developed framework which comprises of social factors, affect towards use, complexity, job fit, long term consequences, facilitating conditions, experience in technology use as independent variables.

\section{Research methodology}

\subsection{Research background}

This study adopts a quantitative research method and data was collected from academic staffs from Malaysia institutions that adopts both digital learning such as Massive open online course (MOOC), LMS, etc. in teaching and learning activities. Moreover, each academic staff that participated in the survey utilize e-learning system as a platform to upload teaching material (e.g., links, power point,.doc,.pdf files, etc.), announce course schedule/timetable, carryout course description and summary, manage class assignments submitted, conduct online quiz, and conduct class management in their respective institution.

\subsection{Data collection}

The survey questionnaire was designed in English language. The questionnaire was sent to ten experts to correct the questionnaire for face and content validity to verify 


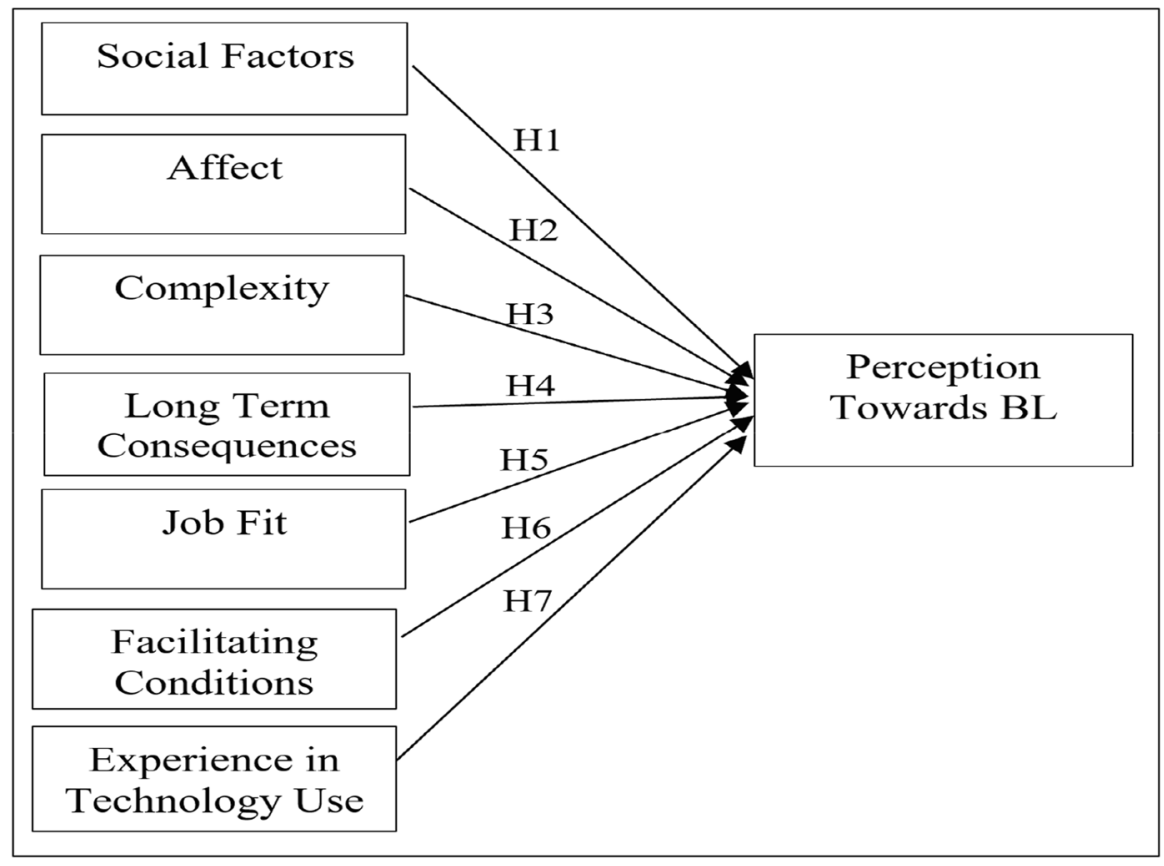

Fig. 4 Proposed framework

the correctness of the questionnaires in the pre-test phase, after which pre-test was carried out and data was collected from ten academic staffs to evaluate how the preliminary assess the survey questions. After which the survey was deployed to other purposive selected academic staffs who have prior experience on BL adoption in their institutions. The data collection involves a survey of academic staffs in Malaysia institutions from within 2019 (January to March). The respondents were asked to provide email at the end of the survey if they are interested to partake in a raffle draw where randomly selected winners were rewarded with gifts. The survey was deployed on lime survey platform to collect the response from the participants.

The questionnaire included demographic question (gender, date of birth, nationality, job title, qualification, IT experience, employment type, educational field) measured using ordinal measurement. Based on proposed framework (see Fig. 4) the questionnaire is designed to measure lecturer's perception towards BL assessed based on a 5-point Likert scale from 1 to 5, similar to prior research (Yeou, 2016; Ghazal et al., 2017; Anthony et al., 2019). The questionnaire items were derived from prior BL studies (see Table 5 in Appendix) which comprised of affect (three items), complexity (three items), job fit (four items), long term consequences (three items), social factors (three items), facilitating conditions (four items), experience in technology use (four items), and perception towards BL (four items). Table 5 depicts the questionnaire indicators and sources. A total of 544 samples were received, but 131 datasets were removed due to partial data provided resulting to 413 complete datasets. 


\section{Results}

SPSS version 23 and Structural Equation Modeling (SEM)-Partial Least Squares (PLS) was utilized for data analysis. Data analysis in PLS using SEM provides two main analyses which comprise of the assessment of measurement model and assessment of structural model (verifies relationships among model constructs) (Hair et al., 2021; Anthony Jr, 2019; Teo, 2019). PLS-SEM has been used by prior BL studies (Lin \& Wang, 2012; Lakhal et al., 2013; Yeou, 2016; Bervell \& Umar, 2020; Teo, 2019; Anthony et al., 2019), hence appropriate to be employed in this study.

\subsection{Demographic data}

Table 1 depicts the demographic characteristics of the survey respondents.

\subsection{Descriptive, reliability, and validity}

Findings from Table 2 suggest that the mean scores are greater than 2.5 and the standard deviation values are lower than 1 (Anthony Jr et al., 2018; Bokolo et al., 2021). Furthermore, the reliability refers to the measure to which the factor gives dependable results. Also, validity measures to which degree a factor is different from other factors within the model (Yeou, 2016). Results in Table 2 suggest that the reliability score based on the Cronbach's alpha and Composite Reliability (CR) values are higher than 0.70 as recommended in the literature (Anthony et al., 2020; Hair et al., 2021). Moreover, the convergent validity which assess the items that corresponds to an underlying variable is assessed as seen in Table 2 in respect to the Average Variance Extracted (AVE) which value should be higher than 0.50 (Hair et al., 2021). In addition, results from Table 2 depicts that items loaded are greater than the minimum value of 0.4 as suggested in the literature (Lin \& Wang, 2012), thus no items were removed as all items are higher than 0.4 benchmark.

Next, the discriminate validity is employed to measure the difference level between the factors and their corresponding items. Hair et al. (2021) suggested that the AVE value should be higher than 0.50 for all factors at $50 \%$ variance (Anthony Jr, 2019). The results presented in Table 3 suggest that all factors adequately greater than 0.5 .

\subsection{Framework validation}

\subsubsection{Validation of factors influence towards BL perception ( $\mathrm{H} 1-\mathrm{H} 7)$}

This phase involves the test of the framework hypotheses $(\mathrm{H} 1-\mathrm{H} 7)$ by examining the path significance levels of each hypothesis. Results from Fig. 5 and Table 4 depicts the two-tail test by measuring the path coefficients value $(\beta)$ which evaluates the association between factors based on their degree of significant levels ( $p$-value) which is significant when $\mathrm{p} \leq 0.05$. Besides, the coefficient of determination termed $\mathrm{R}^{2}$ is used to 
Table 1 Characteristic of lecturer questionnaire participants $(n=413)$

\begin{tabular}{|c|c|c|}
\hline Profile & Options & Frequency \\
\hline \multirow[t]{2}{*}{ Gender } & Male & 130 \\
\hline & Female & 283 \\
\hline \multirow[t]{6}{*}{ Date of birth } & 1950-1959 & 4 \\
\hline & $1960-1969$ & 64 \\
\hline & $1970-1979$ & 145 \\
\hline & 1980-1989 & 179 \\
\hline & 1990-1999 & 11 \\
\hline & 2000 & 10 \\
\hline \multirow[t]{2}{*}{ Nationality } & Malaysian & 402 \\
\hline & International & 11 \\
\hline \multirow[t]{6}{*}{ Job title } & Tutor or Equivalent & 7 \\
\hline & Lecturer or Equivalent & 275 \\
\hline & Senior Lecturer/Assistant Professor or Equivalent & 99 \\
\hline & Associate Professor or Equivalent & 10 \\
\hline & Professor & 5 \\
\hline & Others & 17 \\
\hline \multirow[t]{6}{*}{ Qualification } & Doctorate & 97 \\
\hline & Master's Degree & 207 \\
\hline & Bachelor's Degree & 92 \\
\hline & Advance Diploma & 5 \\
\hline & Diploma or Equivalent & 11 \\
\hline & Others & 1 \\
\hline \multirow[t]{8}{*}{ IT experience } & $1-5$ & 108 \\
\hline & $6-10$ & 115 \\
\hline & $11-15$ & 71 \\
\hline & $16-20$ & 70 \\
\hline & $21-25$ & 29 \\
\hline & $26-30$ & 11 \\
\hline & $31-35$ & 6 \\
\hline & $36-40$ & 3 \\
\hline \multirow[t]{3}{*}{ Employment type } & Permanent & 383 \\
\hline & Contract & 23 \\
\hline & Part time & 7 \\
\hline
\end{tabular}


Table 1 (continued)

\begin{tabular}{lll}
\hline Profile & Options & Frequency \\
\hline Educational field & Management/Business/Accounting/Finance & 116 \\
Sciences & 11 \\
Technology & 3 \\
Engineering & 112 \\
Computer science & 41 \\
Social science & 29 \\
Health and Medicine & 5 \\
Arts and Humanities & 38 \\
Agriculture & 5 \\
Law & 3 \\
Mathematics and Statistics & 20 \\
Architecture and Building & 4 \\
Others & 19 \\
\hline
\end{tabular}

measure the predictive significance of the hypotheses. Next, the t-value is employed to measure the effects of each hypothesis, which is based on the regression coefficients as listed in Table 4, where t-value should be greater than 1.96 (Hair et al., 2021).

As seen in Table 4 and Fig. 5 all t-values are higher than 1.96. Furthermore, results from Table 4 also depict the $\beta$ and $\mathrm{R}^{2}$ values which is the different path coefficients ranking of the hypotheses, where experience in technology use (H7) has the strongest effect of $0.903(0.815)$. Next is, job fit (H5) with 0.881 (0.776), then facilitating conditions (H6) with 0.853 (0.727). Subsequent hypothesis is social factors (H1) with 0.845 (0.714), followed by long term consequences (H5) with 0.761 (0.580), then affect towards use (H2) with $0.714(0.510)$, and lastly complexity (H3) with $0.622(0.387)$. Therefore, the hypothesized path relationships $(\mathrm{H} 1-\mathrm{H} 7)$ are statistically significant since the $\beta$ and $\mathrm{R}^{2}$ values are greater than 0.1 and $\mathrm{p}$-values are lower than 0.05 (Hair et al., 2021). Moreover, the results suggest that H7 "experience in technology use" is the strongest factor. Hence, the result indicates that lecturers with prior computer training are have more positive perception towards using BL for academic activities. 
Table 2 Descriptive, reliability and validity analysis

\begin{tabular}{|c|c|c|c|c|c|c|c|}
\hline Factors & Items & Loadings & $\begin{array}{l}\text { Cronbach's } \\
\text { alpha }(\alpha)\end{array}$ & $\begin{array}{l}\text { Composite } \\
\text { reliability } \\
\text { (CR) }\end{array}$ & $\begin{array}{l}\text { Average variance } \\
\text { extracted (AVE) }\end{array}$ & Mean & $\begin{array}{l}\text { Standard } \\
\text { deviation } \\
\text { (SD) }\end{array}$ \\
\hline \multirow[t]{3}{*}{ Social factors } & SF1 & 0.893 & \multirow[t]{3}{*}{0.851} & \multirow[t]{3}{*}{0.896} & \multirow[t]{3}{*}{0.770} & \multirow[t]{3}{*}{3.9306} & \multirow[t]{3}{*}{0.66870} \\
\hline & SF2 & 0.873 & & & & & \\
\hline & SF3 & 0.867 & & & & & \\
\hline \multirow[t]{3}{*}{ Affect } & AF1 & 0.853 & \multirow[t]{3}{*}{0.826} & \multirow[t]{3}{*}{0.910} & \multirow[t]{3}{*}{0.742} & \multirow[t]{3}{*}{4.0040} & \multirow[t]{3}{*}{0.67888} \\
\hline & AF2 & 0.885 & & & & & \\
\hline & AF3 & 0.845 & & & & & \\
\hline \multirow[t]{3}{*}{ Complexity } & CM1 & 0.836 & \multirow[t]{3}{*}{0.735} & \multirow[t]{3}{*}{0.851} & \multirow[t]{3}{*}{0.742} & \multirow[t]{3}{*}{3.8636} & \multirow[t]{3}{*}{0.61311} \\
\hline & $\mathrm{CM} 2$ & 0.858 & & & & & \\
\hline & CM3 & 0.731 & & & & & \\
\hline \multirow{3}{*}{$\begin{array}{l}\text { Long term conse- } \\
\text { quences }\end{array}$} & LT1 & 0.890 & \multirow[t]{3}{*}{0.843} & \multirow[t]{3}{*}{0.906} & \multirow[t]{3}{*}{0.762} & \multirow[t]{3}{*}{3.9023} & \multirow[t]{3}{*}{0.73029} \\
\hline & LT2 & 0.906 & & & & & \\
\hline & LT3 & 0.822 & & & & & \\
\hline \multirow[t]{4}{*}{ Job fit } & JF1 & 0.885 & \multirow[t]{4}{*}{0.915} & \multirow[t]{4}{*}{0.940} & \multirow[t]{4}{*}{0.797} & \multirow[t]{4}{*}{3.7373} & \multirow[t]{4}{*}{0.77604} \\
\hline & JF2 & 0.904 & & & & & \\
\hline & JF3 & 0.889 & & & & & \\
\hline & JF4 & 0.893 & & & & & \\
\hline \multirow{4}{*}{$\begin{array}{l}\text { Facilitating condi- } \\
\text { tions }\end{array}$} & $\mathrm{FC} 1$ & 0.907 & 0.895 & 0.927 & 0.761 & 3.9292 & 0.69497 \\
\hline & $\mathrm{FC} 2$ & 0.871 & & & & & \\
\hline & FC3 & 0.846 & & & & & \\
\hline & $\mathrm{FC} 4$ & 0.864 & & & & & \\
\hline Experience in & ET1 & 0.883 & 0.900 & 0.930 & 0.770 & 3.8251 & 0.74866 \\
\hline technology use & ET2 & 0.898 & & & & & \\
\hline & ET3 & 0.890 & & & & & \\
\hline & ET4 & 0.838 & & & & & \\
\hline Perception & PT1 & 0.915 & 0.927 & 0.948 & 0.820 & 3.8753 & 0.73769 \\
\hline towards BL & PT2 & 0.901 & & & & & \\
\hline & PT3 & 0.901 & & & & & \\
\hline & PT4 & 0.906 & & & & & \\
\hline
\end{tabular}

For Mean $1=$ least significant; 2 = fairly significant; $3=$ significant; $4=$ very significant; and $5=$ most significant 


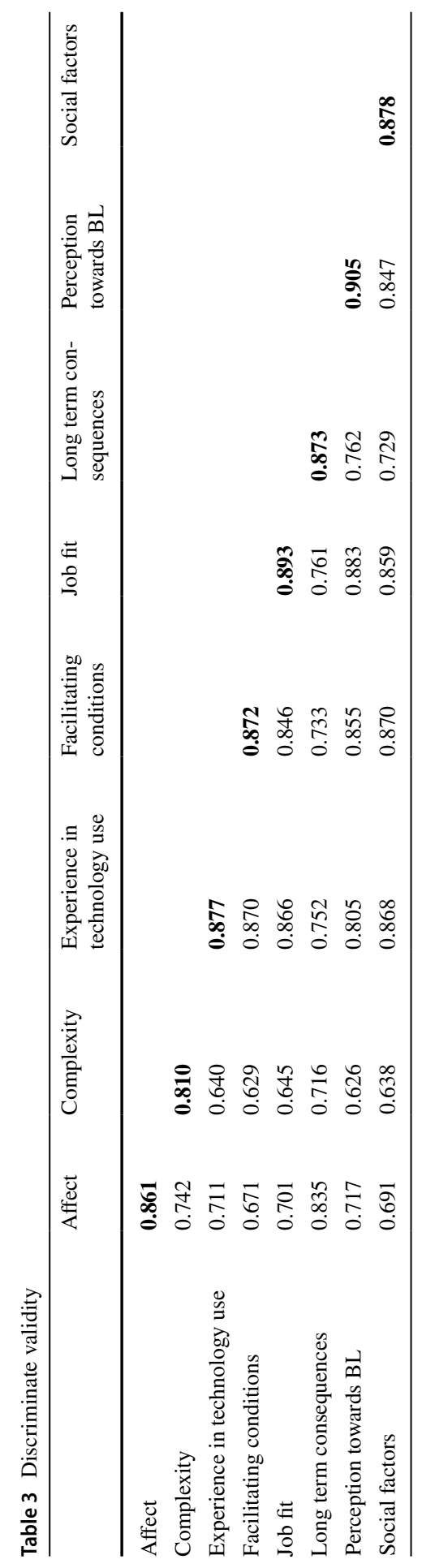




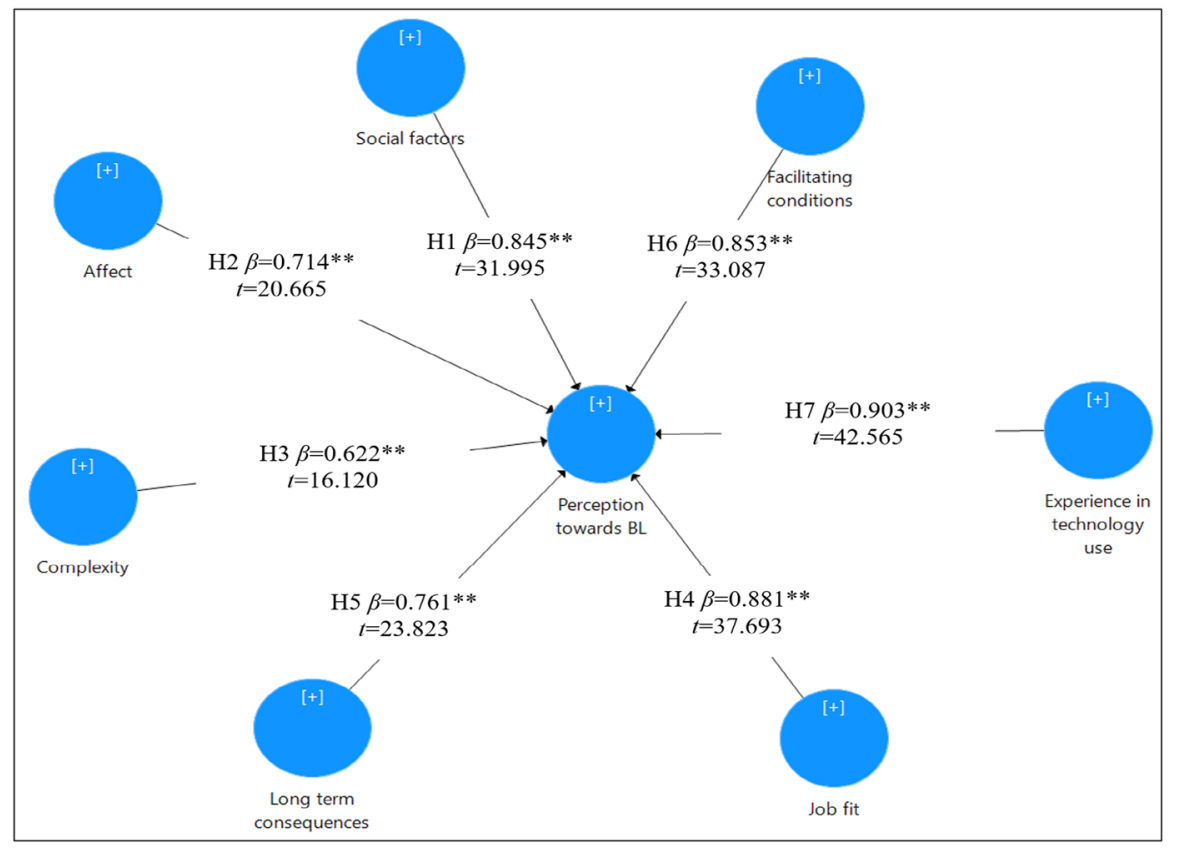

Fig. 5 Results for framework validation

\section{Discussion and implications}

\subsection{Discussion}

The number of studies that empirically examined the factors that influences academic staff's perception towards adopting BL is extremely limited. Therefore, this article addresses these concerns by reporting on the development and validation of a framework grounded on model of personal computer utilization theory to measure factors that influence lecturers' perception of using BL to improve teaching quality in higher education. Data was collected from 413 lecturers across Malaysia institutions and analyzed using SPSS and PLS-SEM. Results from this study provide empirical support for the relationship between social factors and lecturers perception towards BL for teaching. This result is consistent with findings from prior studies (Brand et al., 2011; Riemenschneider et al., 2002), where the authors stated that social factors refer to individual's values, norms, and roles that influences lecturers' behaviors towards BL adoption. Accordingly, the result confirm that the social factors influence lecturers' subjective culture which depend on his/her interactions with peers and colleagues. Thus, if the lecturer perceive that his peers use BL for teaching that can change his/her perception towards adopting BL for teaching.

The results also indicate that affect towards use positively influences lecturer's perception towards BL. This factor is considered an important construct of lecturer's 


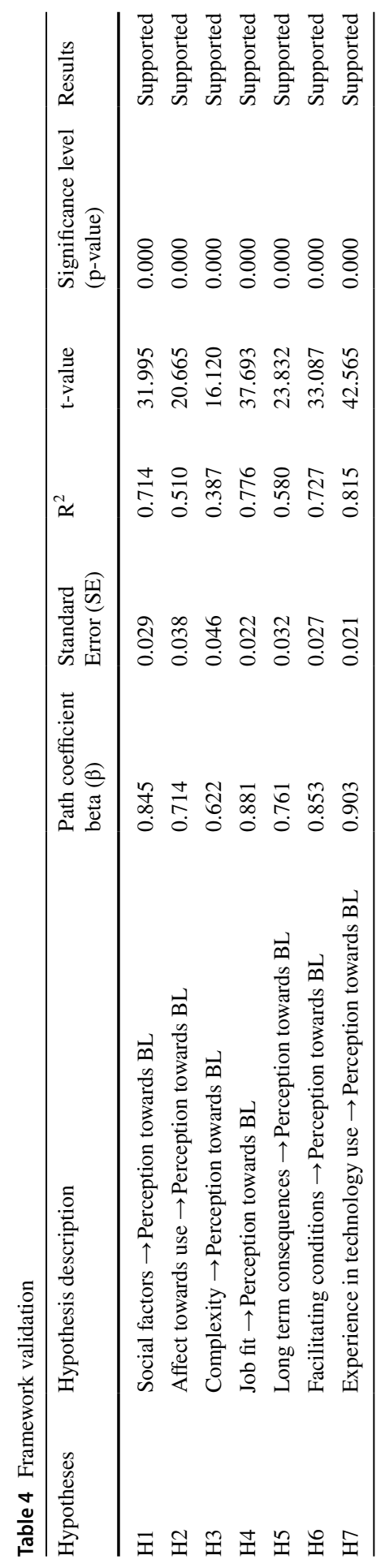


behavioral towards use of BL approach (Anthony et al., 2019). This result confirms prior work (Lwoga \& Komba, 2015), in which the findings from the authors suggested that the negative or positive emotional reactions of the lecturers determines if the lecturer will use BL. Therefore, affective factor of attitudes relates to lecturer like/ dislike association of BL. Findings from this study suggest that statistical significance was observed between complexity and lecturer's perception towards BL (Gawande, 2016). This suggest that the complexity or perceived ease of use of BL will motivate if lecturers use BL. Thus, results from prior studies (Al-Khaldi \& Wallace, 1999; Kocaleva et al., 2014) confirmed that the degree to which lecturers expects the system to be free of effort positively correlates with their perception. The study also found that job fit significantly predicts perception towards BL. Where, job fit refer to BL potential for enhancing teaching performance and improving pedagogical productivity (Gawande, 2015). This result suggests that perceived usefulness of BL will influence the potential teaching outcomes to be derived from BL which can reduce the time needed for accomplishing teaching activities (Kocaleva et al., 2014).

Further, this study found that long term consequences positively influence lecturer's perception towards $\mathrm{BL}$, which is consistent with results reported by Kocaleva et al. (2014); Dečman (2015) which revealed that long term consequences which relates to the impact BL outcomes will have in future, such as increasing the flexibility of teaching or improving the prospects for more course curriculum design. Additionally, the results suggest that facilitating conditions of BL predicts lecturer's perception towards BL. According to Radovan and Kristl (2017) facilitating conditions involves the availability or provision of support systems that aids BL activities. Besides, facilitating conditions are factors that make BL easy to be adopted by lecturers for teaching (Dečman, 2015). Besides, experience in technology use appears to have a significant influence on lecturer's perception towards BL. This result is in line with findings from prior studies conducted by Gawande (2015); Saleem et al. (2016), where the authors suggested that lecturers that have prior experience in the use of computers are most probably use BL for teaching, and this decreases anxieties and negative attitudes toward BL utilization.

\subsection{Implications of study}

This study has potential theoretical, practical, and future research implications for BL from the lens of academic staffs. Respectively, this study has several implications for lecturers and decision makers in higher education institutions by providing insights into how to the perception of lecturers regarding BL.

\subsubsection{Research implications}

This study provides implication for future research in BL by providing researchers with guidance regarding factors that influence lecturers' perception to use BL derived from MPCU theory. Therefore, this research is a one of the first studies that integrates 
MPCU theory to develop a model to examine lecturers' perception in BL environment. Overall, the results of the present study suggest that MPCU theory can provide empirical evidence of lecturers' perception of BL approach for teaching. Based on MPCU theory this research provides valuable insights into technology use in academic setting. Overall, this research adds to the body of knowledge about behaviour theory in BL environment. Thus, the utilizing of MPCU theory as a base theory in the context of lecturers' perception towards BL for teaching provide possible prospects for future research on the investigation of various theoretical perspectives to understand lecturers' BL usage intentions.

Theoretically, findings from this research contribute to existing BL studies by providing an understand, of factors that influence lecturers' perception towards use of BL to improve teaching. Findings from this study offers evidence to institutions' faculty members on their lecturer's perception for the adoption of blended courses and in making improvement where necessary. The proposed framework (see Fig. 4) can be employed by higher education institutions to enhance their understanding of what makes lecturers adopt blended courses. The framework offers an approach that improves the success of lecturer's attitude and can be utilized to provide feedback for how to improve current BL design.

\subsubsection{Practical implications}

The model developed in this study provide better understanding into how institutions can develop initiatives (see Table 5) to encourage continuous usage of BL among lecturers in their respective institutions. Moreover, findings from this study are useful to e-learning administration to identify factors to be considered in developing appropriate policies to promote usage of BL in higher education. The results can be helpful in preparing approach to support lecturers in deploying innovative approaches, promoting the implementation of technology to enhance learning and teaching outcomes. The findings can be used for initiating methodologies to improve BL practice in institutions and beyond. From practical perspective, the proposed framework aims to support lecturers make pedagogically informed design decisions that make appropriate utilization of BL as a delivery method.

Specifically, this study provides faculties and others interested in BL deployment with information regarding how to support and change the behaviour among their respective institutions. Besides, this study provided insight as to where future efforts need to be directed to improve the lecturers experience in Malaysia institutions of higher learning. Furthermore, the findings provided in this article can be used to design pedagogical policies to promotes continuance mindset change of BL approaches among lecturers. Findings from this study provides factors and related items as seen in Appendix that can be considered by higher education in improving the perception of academic staffs in using BL for teaching. Also, BL scenario in Fig. 2 can be employed to improve skills in designing curriculum using IT for teaching and learning activities in institutions. 


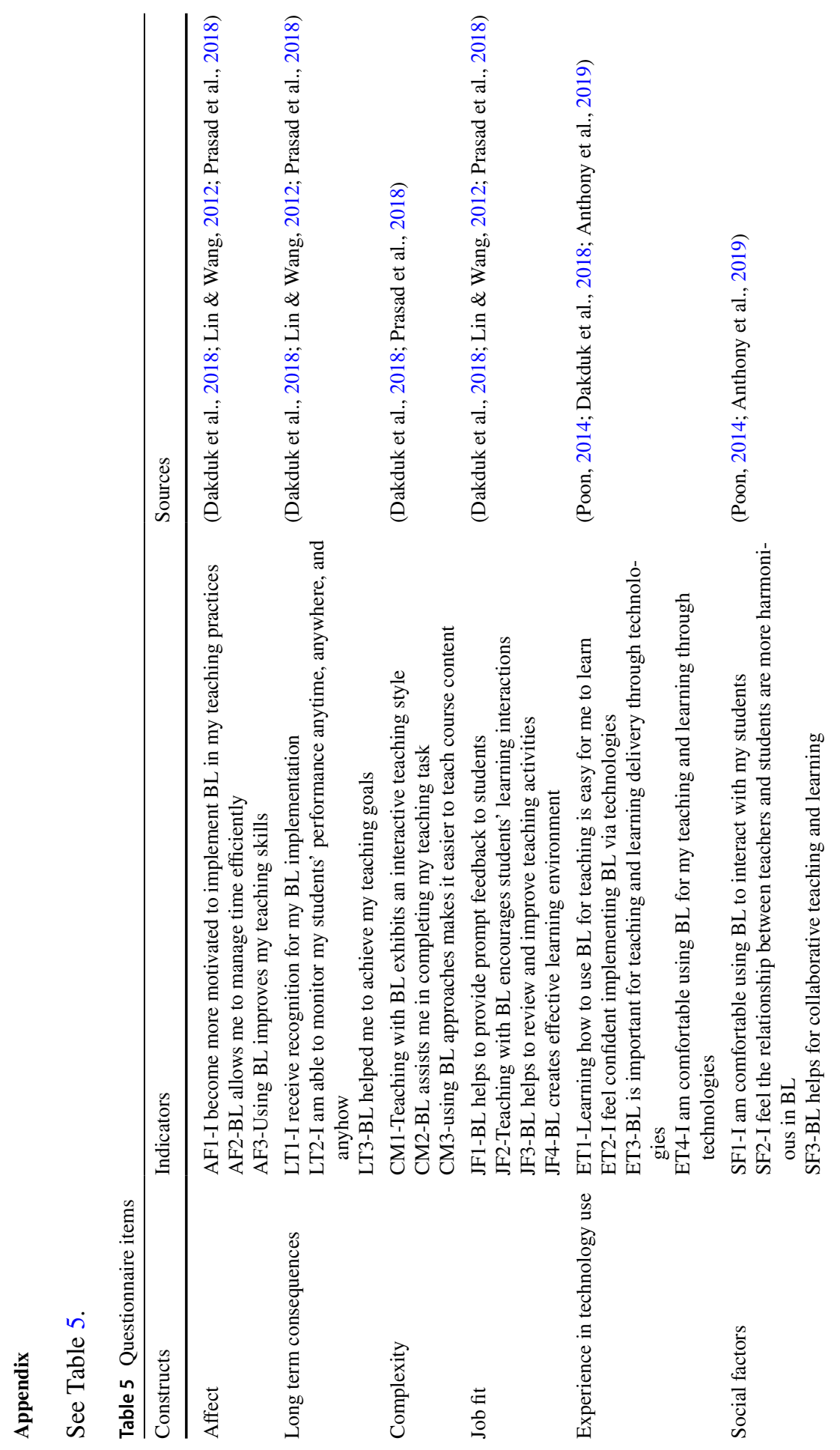




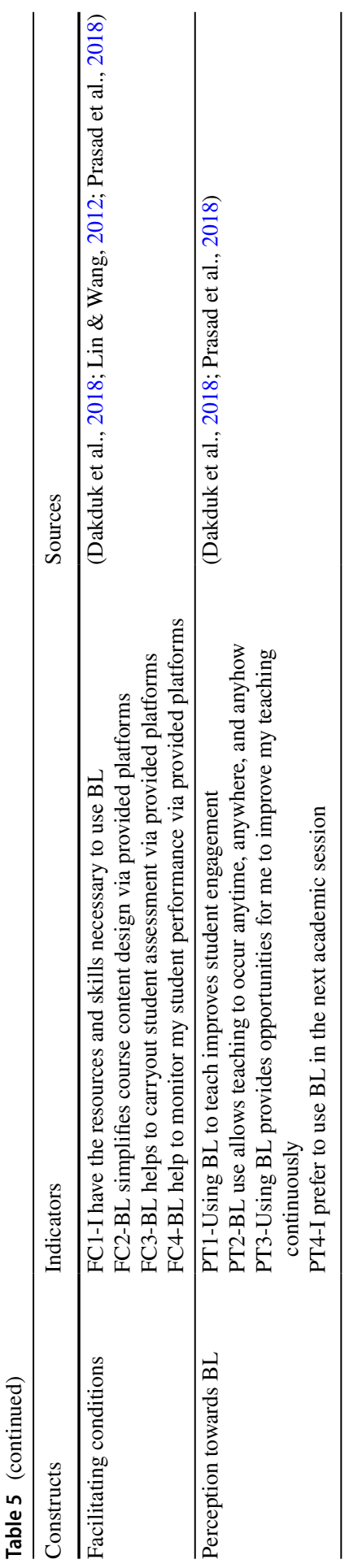




\section{Conclusion}

This study develops a framework grounded on model of personal computer utilization theory to examine the factors that influence lecturers' perception of BL to improve teaching quality in higher education. Data was collected using questionnaire instrument from lecturers across institutions within Malaysia and analyzed using SPSS and PLS-SEM. The statistical results confirm that the factors impact lecturers' perception towards BL as a teaching method. Moreover, this study provides implications to educationalist towards providing the required insights as to how institutions can enhance lecturers' perception to support BL approaches. In addition, findings provided in this study can be utilized to design policies that support satisfaction of BL approach among academic staffs.

This study has few limitations. First, the result from this study is from Malaysia institutions thus cannot be generalized to other countries. Secondly, this study employs quantitative survey to collect data which lacks the ability to employ indepth investigation. Thirdly, this study was conducted among lecturers only. Finally, this study did not analyze effect for type of institution as the data was gathered from a different universities, colleges, and polytechnics. Therefore, future works may include collecting data from other countries. Besides, qualitative case study can be employed to collect data using open-ended interview to get in-depth understanding of the framework. Also, future research will examine type of institutions to assess the relevance of individual perceptions of BL for universities, colleges, and polytechnics. Lastly, there is need to investigate perception of administrators in higher education that manage BL approaches.

Acknowledgements This research project is financially supported by the Fundamental Research Grant Scheme (FRGS) from Ministry of Education, Under Universiti Malaysia Pahang Malaysia Grant No. RDU180702.

Funding Open access funding provided by NTNU Norwegian University of Science and Technology (incl St. Olavs Hospital - Trondheim University Hospital).

Open Access This article is licensed under a Creative Commons Attribution 4.0 International License, which permits use, sharing, adaptation, distribution and reproduction in any medium or format, as long as you give appropriate credit to the original author(s) and the source, provide a link to the Creative Commons licence, and indicate if changes were made. The images or other third party material in this article are included in the article's Creative Commons licence, unless indicated otherwise in a credit line to the material. If material is not included in the article's Creative Commons licence and your intended use is not permitted by statutory regulation or exceeds the permitted use, you will need to obtain permission directly from the copyright holder. To view a copy of this licence, visit http://creativecommons.org/licen ses/by/4.0/. 


\section{References}

Abu-Al-Aish, A., \& Love, S. (2013). Factors influencing students' acceptance of m-learning: An investigation in higher education. International Review of Research in Open and Distributed Learning, 14(5), 82-107.

Aguti, B., Wills, G. B., \& Walters, R. J. (2014). An evaluation of the factors that impact on the effectiveness of blended e-learning within universities. In International conference on information society (i-Society 2014) (pp. 117-121).

Ahmed, H. M. S. (2010). Hybrid e-learning acceptance model: Learner perceptions. Decision Sciences Journal of Innovative Education, 8(2), 313-346.

Alhabeeb, A., \& Rowley, J. (2018). E-learning critical success factors: Comparing perspectives from academic staff and students. Computers \& Education, 127, 1-12.

Al-Khaldi, M. A., \& Wallace, R. O. (1999). The influence of attitudes on personal computer utilization among knowledge workers: The case of Saudi Arabia. Information \& Management, 36(4), 185-204.

Almutairi, F., \& White, S. (2018). How to measure student engagement in the context of blended-MOOC. Interactive Technology and Smart Education, 15(3), 262-278.

Anthony Jr, B. (2019). Green information system integration for environmental performance in organizations: An extension of belief-action-outcome framework and natural resource-based view theory. Benchmarking: An International Journal, 26(3), 1033-1062.

Anthony Jr, B., Majid, M. A., \& Romli, A. (2018). A collaborative agent based green IS practice assessment tool for environmental sustainability attainment in enterprise data centers. Journal of Enterprise Information Management., 31(5), 771-795.

Anthony, B., Kamaludin, A., Romli, A., Raffei, A. F. M., Abdullah, A., Ming, G. L., Shukor, N. A., Nordin, M. S., \& Baba, S. (2019). Exploring the role of blended learning for teaching and learning effectiveness in institutions of higher learning: An empirical investigation. Education and Information Technologies, 24(6), 3433-3466.

Anthony, B., Majid, M. A., \& Romli, A. (2020). Green IS diffusion in organizations: A model and empirical results from Malaysia. Environment, Development and Sustainability, 22(1), 383-424.

Bath, D., \& Bourke, J. (2011). The blending of blended learning: An experiential approach to academic staff development. In ASCILITE (pp. 4-7).

Bervell, B., \& Umar, I. N. (2020). Blended learning or face-to-face? Does Tutor anxiety prevent the adoption of Learning Management Systems for distance education in Ghana? Open Learning: The Journal of Open, Distance and e-Learning, 35(2), 159-177.

Bokolo, A. J. (2021). Examining the adoption of emergency remote teaching and virtual learning during and after COVID-19 pandemic. International Journal of Educational Management. https://doi.org/ 10.1108/IJEM-08-2020-0370

Bokolo, A., Maureen, G. P., \& Majid, M. A. (2021). A web deployed multi-agent based approach for student-lecturer appointment scheduling in institutions of higher learning. Journal of Physics: Conference Series, $1830(1), 012007$.

Bokolo Jr, A., Kamaludin, A., Romli, A., Mat Raffei, A. F., AL Eh Phon, D. N., Abdullah, A., Ming, G. L., Shukor, N. A., Nordin, M. S., \& Baba, S. (2020). A managerial perspective on institutions' administration readiness to diffuse blended learning in higher education: Concept and evidence. Journal of Research on Technology in Education, 52(1), 37-64.

Bowyer, J., \& Chambers, L. (2017). Evaluating blended learning: Bringing the elements together. Research Matters: A Cambridge Assessment Publication, 23, 17-26.

Brand, J., Kinash, S., Mathew, T., \& Kordyban, R. (2011). iWant does not equal iWill: Correlates of mobile learning with iPads, e-textbooks, BlackBoard Mobile Learn and a blended learning experience. In Proceedings ASCILITE 2011: 28th annual conference of the Australasian society for computers in learning in tertiary education: Changing demands, changing directions (pp. 168-178). University of Tasmania.

Carbonell, K. B., Dailey-Hebert, A., \& Gijselaers, W. (2013). Unleashing the creative potential of faculty to create blended learning. The Internet and Higher Education, 18, 29-37.

Chong, S., Cheah, H. M., \& Low, E. L. (2010). Perceptions of student teachers in a blended learning environment. International Journal of Innovation and Learning, 8(4), 345-359.

Dakduk, S., Santalla-Banderali, Z., \& van der Woude, D. (2018). Acceptance of blended learning in executive education. SAGE Open, 8(3), 2158244018800647. 
Dečman, M. (2015). Modeling the acceptance of e-learning in mandatory environments of higher education: The influence of previous education and gender. Computers in Human Behavior, 49, 272-281.

Deng, R., Benckendorff, P., \& Gannaway, D. (2019). Progress and new directions for teaching and learning in MOOCs. Computers \& Education, 129, 48-60.

Gawande, V. (2015). Development of blended learning model based on the perceptions of students at higher education institutes in Oman. International Journal of Computer Applications, 114(1), $38-45$.

Gawande, V. (2016). Analysis of faculty perceptions toward blended learning adoption at higher education institutes in Oman. International Journal of Computer Applications, 140(9), 50-54.

Ghazal, S., Aldowah, H., \& Umar, I. (2017, April). Critical factors to learning management system acceptance and satisfaction in a blended learning environment. In International conference of reliable information and communication technology (pp. 688-698). Springer.

Graham, C. R., Woodfield, W., \& Harrison, J. B. (2013). A framework for institutional adoption and implementation of blended learning in higher education. The Internet and Higher Education, 18, 4-14.

Hair, J. F., Jr., Hult, G. T. M., Ringle, C. M., \& Sarstedt, M. (2021). A primer on partial least squares structural equation modeling (PLS-SEM). Sage Publications.

Haron, H., Abbas, W. F., \& Abd Rahman, N. A. (2012). The adoption of blended learning among Malaysian academicians. Procedia-Social and Behavioral Sciences, 67, 175-181.

Ho, W. Y. (2017). A review of blended synchronous learning. International Journal of Social Media and Interactive Learning Environments, 5(4), 278-291.

Jnr, B. A. (2021). Institutional factors for faculty members' implementation of blended learning in higher education. Education + Training, 63(5), 701-719.

Jnr, B. A., Kamaludin, A., Romli, A., Raffei, A. F. M., Phon, D. N. A. L. E., Abdullah, A., Ming, G. L., Shukor, N. A., Nordin, M. S. \& Baba, S. (2021). An integrative framework to investigate the impact of blended learning adoption in higher education: A theoretical perspective. International Journal of Technology Enhanced Learning, 13(2), 182-207.

Jnr, B. A., Kamaludin, A., Romli, A., Raffei, A. F. M., Phon, D. N. A. E., Abdullah, A., Ming, G. L., Shukor, N. A., Nordin, M. S., \& Baba, S. (2020). Predictors of blended learning deployment in institutions of higher learning: Theory of planned behavior perspective. The International Journal of Information and Learning Technology, 37(4), 179-196.

Kocaleva, M., Stojanovic, I., \& Zdravev, Z. (2014). Research on UTAUT application in higher education institutions. In International conference on information technology and development of education (pp. 34-38).

Kundu, A., Bej, T., \& Rice, M. (2021). Time to engage: Implementing math and literacy blended learning routines in an Indian elementary classroom. Education and Information Technologies, 26(1), 1201-1220.

Lakhal, S., Khechine, H., \& Pascot, D. (2013). Student behavioural intentions to use desktop video conferencing in a distance course: Integration of autonomy to the UTAUT model. Journal of Computing in Higher Education, 25(2), 93-121.

Lin, W. S., \& Wang, C. H. (2012). Antecedences to continued intentions of adopting e-learning system in blended learning instruction: A contingency framework based on models of information system success and task-technology fit. Computers \& Education, 58(1), 88-99.

López-Pérez, M. V., Pérez-López, M. C., \& Rodríguez-Ariza, L. (2011). Blended learning in higher education: Students' perceptions and their relation to outcomes. Computers \& Education, 56(3), $818-826$.

Lwoga, E. T., \& Komba, M. (2015). Antecedents of continued usage intentions of web-based learning management system in Tanzania. Education + Training, 57, 738.

Mondi, M., Woods, P., \& Rafi, A. (2007). Students' 'uses and gratification expectancy' conceptual framework in relation to E-learning resources. Asia Pacific Education Review, 8(3), 435-449.

Monk, E. F., Guidry, K. R., Pusecker, K. L., \& Ilvento, T. W. (2020). Blended learning in computing education: It's here but does it work? Education and Information Technologies, 25(1), 83-104.

Owston, R., Wideman, H., Murphy, J., \& Lupshenyuk, D. (2008). Blended teacher professional development: A synthesis of three program evaluations. The Internet and Higher Education, 11(3-4), 201-210.

Padilla-Meléndez, A., del Aguila-Obra, A. R., \& Garrido-Moreno, A. (2013). Perceived playfulness, gender differences and technology acceptance model in a blended learning scenario. Computers \& Education, 63, 306-317. 
Park, Y., Yu, J. H., \& Jo, I. H. (2016). Clustering blended learning courses by online behavior data: A case study in a Korean higher education institute. The Internet and Higher Education, 29, 1-11.

Poon, J. (2012). Use of blended learning to enhance the student learning experience and engagement in property education. Property Management, 30(2), 129-156.

Poon, J. (2014). A cross-country comparison on the use of blended learning in property education. Property Management, 32(2), 154-175.

Porter, W. W., Graham, C. R., Bodily, R. G., \& Sandberg, D. S. (2016). A qualitative analysis of institutional drivers and barriers to blended learning adoption in higher education. The Internet and Higher Education, 28, 17-27.

Prasad, P. W. C., Maag, A., Redestowicz, M., \& Hoe, L. S. (2018). Unfamiliar technology: Reaction of international students to blended learning. Computers \& Education, 122, 92-103.

Radovan, M., \& Kristl, N. (2017). Acceptance of technology and its impact on teachers' activities in virtual classroom: Integrating UTAUT and CoI into a combined model. Turkish Online Journal of Educational Technology-TOJET, 16(3), 11-22.

Rahman, N. A. A., Hussein, N., \& Aluwi, A. H. (2015). Satisfaction on blended learning in a public higher education institution: What factors matter? Procedia-Social and Behavioral Sciences, 211, 768-775.

Riemenschneider, C. K., Hardgrave, B. C., \& Davis, F. D. (2002). Explaining software developer acceptance of methodologies: A comparison of five theoretical models. IEEE Transactions on Software Engineering, 28(12), 1135-1145.

River, J., Currie, J., Crawford, T., Betihavas, V., \& Randall, S. (2016). A systematic review examining the effectiveness of blending technology with team-based learning. Nurse Education Today, 45, 185-192.

Saleem, N. E., Al-Saqri, M. N., \& Ahmad, S. E. (2016). Acceptance of Moodle as a teaching/learning tool by the faculty of the department of information studies at Sultan Qaboos University, Oman based on UTAUT. International Journal of Knowledge Content Development \& Technology, 6(2), 5-27.

Sari, R., \& Karsen, M. (2016). An empirical study on blended learning to improve quality of learning in higher education. In 2016 International conference on information management and technology (ICIMTech) (pp. 235-240).

So, H. J., \& Brush, T. A. (2008). Student perceptions of collaborative learning, social presence and satisfaction in a blended learning environment: Relationships and critical factors. Computers \& Education, 51(1), 318-336.

Taherdoost, H. (2018). A review of technology acceptance and adoption models and theories. Procedia Manufacturing, 22, 960-967.

Tarhini, A., Al-Busaidi, K. A., Mohammed, A. B., \& Maqableh, M. (2017). Factors influencing students' adoption of e-learning: a structural equation modeling approach. Journal of International Education in Business, 10, 164.

Teo, T. (2019). Students and teachers' intention to use technology: Assessing their measurement equivalence and structural invariance. Journal of Educational Computing Research, 57(1), 201-225.

Thompson, R. L., Higgins, C. A., \& Howell, J. M. (1991). Personal computing: Toward a conceptual model of utilization. MIS Quarterly, 15, 125-143.

Thompson, R. L., Higgins, C. A., \& Howell, J. M. (1994). Influence of experience on personal computer utilization: Testing a conceptual model. Journal of Management Information Systems, 11(1), $167-187$.

Triandis, H. C. (1979). Values, attitudes, and interpersonal behavior. University of Nebraska Press.

Tuparova, D., \& Tuparov, G. (2011). Implementation of blended learning scenarios for training of school teachers. In 2011 14th International conference on interactive collaborative learning (pp. 285-289).

Wang, C. (2021). Employing blended learning to enhance learners' English conversation: A preliminary study of teaching with Hitutor. Education and Information Technologies, 26(2), 2407-2425.

Wong, L., Tatnall, A., \& Burgess, S. (2014). A framework for investigating blended learning effectiveness. Education + Training., 56(2/3), 233-251.

Wong, K. T., Hwang, G. J., Choo Goh, P. S., \& Mohd Arrif, S. K. (2020). Effects of blended learning pedagogical practices on students' motivation and autonomy for the teaching of short stories in upper secondary English. Interactive Learning Environments, 28(4), 512-525.

Yeou, M. (2016). An investigation of students' acceptance of Moodle in a blended learning setting using technology acceptance model. Journal of Educational Technology Systems, 44(3), 300-318.

Publisher's note Springer Nature remains neutral with regard to jurisdictional claims in published maps and institutional affiliations. 